\title{
First-Year Life Science Students' Understanding of the Role of Plants in the Ecosystem-A Concept Network Analysis
}

\author{
Ilona Södervik ${ }^{1, *}$, Maija Nousiainen ${ }^{2}$ (D) and Ismo. T. Koponen ${ }^{2}(\mathbb{D}$ \\ 1 Centre for University Teaching and Learning (HYPE), University of Helsinki, 00014 Helsinki, Finland \\ 2 Department of Physics, University of Helsinki, 00014 Helsinki, Finland; maija.nousiainen@helsinki.fi (M.N.); \\ ismo.koponen@helsinki.fi (I.T.K.) \\ * Correspondence: ilona.sodervik@helsinki.fi
}

\section{check for} updates

Citation: Södervik, I.; Nousiainen, M.; Koponen, I..T. First-Year Life Science Students' Understanding of the Role of Plants in the Ecosystem-A Concept Network Analysis. Educ. Sci. 2021, 11, 369. https: / / doi.org/10.3390/educsci 11080369

Academic Editors: Maria José Sousa, Fátima Suleman, Pere Mercadé Melé and Jesús Molina Gómez

Received: 31 May 2021

Accepted: 16 July 2021

Published: 21 July 2021

Publisher's Note: MDPI stays neutral with regard to jurisdictional claims in published maps and institutional affiliations.

Copyright: (c) 2021 by the authors. Licensee MDPI, Basel, Switzerland. This article is an open access article distributed under the terms and conditions of the Creative Commons Attribution (CC BY) license (https:// creativecommons.org/licenses/by/ $4.0 /)$.

\begin{abstract}
The purpose of this study is to increase the understanding about undergraduate life science students' conceptions concerning the role of photosynthesizing plants in the ecosystem, utilizing a network analysis method. Science learning requires the integration and linking of abstract and often counterintuitive concepts successfully into multifaceted networks. The quality of these networks, together with their abilities to communicate via the language of science, influences students' success in academic, verbal problem-solving tasks. This study contributes to investigating students' understanding, utilizing a modern network analysis method in exploring first-year university life science students' written answers. In this study, a total of 150 first-year life science students answered two open-ended tasks related to the role of photosynthesizing plants in the ecosystem. A network analysis tool was used in exploring the occurrence of different-level science concepts and the interrelatedness between these concepts in students' verbal outputs. The results showed that the richness of concept networks and students' use of macro-concepts were remarkably varied between the tasks. Higher communicability measures were connected to the more abundant existence of macro-concepts in the task concerning the role of plants from the food-chain perspective. In the answers for the task concerning the role of plants regarding the atmosphere, the students operated mainly with single facts, and there were only minor interconnections made between the central concepts. On the basis of these results, the need for more all-encompassing biology teaching concerning complex environmental and socio-economic problems became evident. Thus, methodological and pedagogical contributions are discussed.
\end{abstract}

Keywords: concept; knowledge integration; macro-concept; language of science; network analysis; photosynthesis; biology education; science education; higher education

\section{Introduction}

Research has shown that students come to science classrooms with a heterogeneous level and quality of prior knowledge that significantly influences and sometimes remarkably hinders learning [1-3]. Science learning requires the construction of a solid conceptual knowledge base, which means understanding a large number of abstract, complex and even counterintuitive concepts, their relationships, and the flexible use of this knowledge in problem-solving. This typically poses challenges for many students, not only at elementary and upper-secondary school levels but also in higher education [4-8]. Science operates via abstract scientific concepts (e.g., photosynthesis, ecosystems) that significantly differ from everyday concepts, and, typically, mastering them requires systematic, intentional, and deliberate learning and instruction [9]. As a result of successful science learning, concepts gradually become linked to form complex and hierarchical networks [10]. The richness and organization of these networks play a crucial role in the learning of complex contents and impact the quality of a learner's cognitive processing and problem-solving skills [10].

Text reading and writing are still the most common learning activities in higher education. However, students' verbal outputs for science tasks indicate not only their 
topic-specific conceptions but also their ability to use and operate within science language meaningfully. The language of science builds on interconnected science concepts, and first-year university students are expected to learn to understand and use this disciplinespecific language, with its unique rules, as part of their subject studies. However, this aspect is often more or less ignored in science education, particularly at university level, although it poses challenges for novice students, who may not yet have the appropriate skills to communicate using the language of science that is designed for highly expert audiences [11].

There is a need for sophisticated tools to investigate the quality of students' verbal assignments from the perspectives of richness, quality and the interconnectedness of concepts and language in general. In that regard, network analysis methods that enable exploring and analyzing students' use of science language have shown potential but, typically, these attempts have not considered the semantic hierarchy of concepts related to a particular science phenomenon, or if they have, the analysis has been extremely laborious. Therefore, the aim of this study is to investigate first-year life science students' written answers concerning the role of plants in the ecosystem by utilizing a newly developed network analysis tool that makes it possible to investigate lexicons that reflect students ability to operate with different-level concepts.

\subsection{Learning Science-From Single Facts to Networks of Concepts}

During school years, the students acquire a large number of science concepts and link them in a semantic knowledge network as a part of broader ontologies and explanatory systems. Gradually, the networks are enriched with new concepts and refined so that more and better connections are made between the concepts. The quality of such a network is reflected in structures that are tightly connected and web-like, or hierarchically organized [12-15].

The repeated activation of connections in a knowledge network results in knowledge integration and the forming of so-called macro-concepts, under which many lower-level details, patterns and interrelations of information are organized. Macro-concepts in concept networks can be considered as analogous to key species in food webs so that their occurrence is a prerequisite for several other concepts and contents to be understood. Based on previous studies, the development of macro-concepts shows a move toward more abstracted and integrated concepts in denser knowledge structures [10]. These processes lay the foundation for higher-level cognitive processing, such as problem-solving and case processing, in which conceptual knowledge needs to be flexibly used and applied.

However, the formation of appropriate conceptual understanding does not happen by piling fact over fact; instead, learning science requires a considerable restructuring of conceptual knowledge and conceptual changes in different phases and levels of studies [3]. As a consequence, based on extensive previous studies, we know today that even university students struggle to learn life science concepts and complex contents, and they may have tenacious misconceptions related to the central concepts $[3,16,17]$. The challenges can be partly explained by the complex, dense and even counterintuitive nature of science concepts. Science concepts often develop simplified meanings in everyday language, providing what is seemingly enough explanatory power in everyday contexts, but leading to misinterpretations if used when aiming to explain complex science phenomena in science classrooms [18]. Additionally, science concepts differ, not only from everyday concepts, but they also may have somewhat varying meanings across disciplines. Learning that a familiar word may have an unfamiliar meaning in a new context is likely to be problematic [19]. The concept of energy, for example, is one of the most central and richly connected ideas across all science disciplines that is studied several times during school years in various contexts, and students at different school levels struggle to understand it properly [20]. 


\subsection{Learning the Language of Science}

Learning the language of science has been identified as an important part of learning science. In general, language is central in the development of scientific thinking [21], and learning the specific way to use scientific terms and concepts is central [22]. We can claim that science has its own language because it has its own vocabulary, semantics and syntax and, therefore, some researchers call it the language of science (see, e.g., [23]). These features are important, for example in building meaning between scientific claims, in presenting evidence supporting scientific theories, and other ways to communicate science [24]. The language of science differs greatly from everyday language, and it has been developed for practical reasons. Scientific language is used in communication between scientists and about science; science is reported and communicated through speaking and writing $[22,25]$. Language is then an important technology and an indisputable part of science. Language can be seen as a vehicle for conducting science and building up scientific understanding [26]. However, language can restrict or impede science learning [27], which is why the use of scientific language should receive more attention in science classrooms.

School science is different from real science, but they have a common ground, the language of science. However, science teachers and the authors of science textbooks tend to forget that they are "natives" in the language of science, whereas their students are not [28]. This causes many problems and challenges. For example, the language used in science classrooms differs greatly from the language students are used to [23]. This difference is one of the biggest reasons why students feel that reading science texts is difficult. For many students, the biggest problem in learning science is learning the language of science [29]. It is important to embed students in the language of science with guidance so that they get used to scientific terms and the use of the language [28].

One of the biggest challenges in learning the language of science is learning the science lexicon [23]. When studying science, one must learn a new lexicon (consisting of specific words, terms and concepts) and understand, for example, new phenomena by using the new lexicon. This is a double challenge when compared to learning a foreign language. The language of science is dense in information because it usually consists of scientific terms. These, sometimes very technical, terms are important in science because they enable exact descriptions of phenomena and their relationships. Clauses in scientific texts can be very long and have many nouns. Every noun adds to the amount of information in the clause, but in everyday language, one might use many different clauses to explain a similar kind of situation.

\subsection{Network Analysis in Investigating Students' Use of Science Concepts}

Nowadays, networks and graph theory are applied increasingly often to data analysis in fields where network representation is not an obvious way to analyze data [30]. A recent research paper utilizing a network approach to lexical networks has discussed the importance of extensive lexicons (or vocabularies) when gaining scientific knowledge. An extent lexicon can be regarded as a prerequisite to mastering scientific language and, thus, the ability to use it [31,32].

To sum up, the learning of science concepts and contents poses serious challenges for university students. For investigating this via the verbal outputs of students, we need sophisticated methodological tools. This study contributes to developing new modern methods to investigate this topic by exploring the written answers given by first-year life science students for tasks related to the role of photosynthesizing plants in the ecosystem from the viewpoints of food chains and the atmosphere, utilizing a modern network analysis method. To be precise, we investigate:

(1) Which (macro-)concepts and words do the students use when answering verbally certain questions concerning the role of plants in the ecosystem?

(2) How are the concepts and terms interrelated in students' verbal outputs? 


\section{Materials and Methods}

\subsection{Participants}

The participants comprised 150 first-year life science students from the Faculty of Biological and Environmental Sciences (127 = females; 23 = males) from the University of Helsinki. A total of 56 students had biology as their main subject, while 48 students studied molecular biosciences and 46 studied environmental sciences as their main subject. The participants' ages ranged between 19 and 64, being on average 22.41 years old (SD: 5.17).

The study was performed according to the ethical instructions of the Finnish National Board on Research Integrity (TENK). The participants gave their permission, i.e., filled in the voluntary informed consent form. Participation in the study was voluntary, and the students had the possibility of withdrawing from the research at any time, without any consequences.

\subsection{Measures and Data Collection}

The topic was chosen because photosynthesis is one of the most central concepts in biology, forming the basis for all the energy sources essential to life, from the intake of food to the burning of fossil fuels [33,34]. Photosynthesizing plants also play a very important role in regulating climatic conditions, as photosynthesis controls the budgets of atmospheric gases, such as carbon dioxide. All in all, in this era of climatic, environmental and societal changes, a profound understanding of such a fundamental process as photosynthesis is a necessity for life science students. However, the role of plants in the ecosystem is also often underestimated among scientists, in the well-investigated phenomenon known as 'plant blindness' [35].

Therefore, two open-ended questions that required the application of basic conceptual knowledge were used as measures in this study. The tasks and the instruction were to: "(A) Explain the role of plants in the ecosystem from the food chains point of view"; and "(B) Explain the role of plants in the ecosystem from the viewpoint of the composition of the atmosphere." The tasks required understanding of basic biological phenomena, the most important being photosynthesis. In the curriculum of Finnish upper secondary education, the content of photosynthesis and the role of the phenomenon on a larger scale, including also the perspectives of climate change and energy flow and the cycling of matter in the ecosystem, are handled extensively.

The successful answering of question A required the student to understand that photosynthesizing plants are photoautotrophs and producers of the food chain, transforming solar energy to chemical energy that flows through the food chain for heterotrophs to consume. Additionally, plants play a role in material cycling in the ecosystem. A successful answer for question $B$ required the student to understand that photosynthesizing plants regulate the gas balance of the atmosphere by absorbing carbon dioxide from the atmosphere and releasing oxygen. An increased amount of carbon dioxide in the atmosphere, caused as a result of human activities, is the main reason for the current changes in climate.

A model answer for task A, formulated by two biology university lecturers (with macro-concepts bolded and the contexts relevant for the analysis numbered in parentheses):

Explain the role of plants in the ecosystem from the food chain point of view.

The plants capture the light energy of the Sun and convert it to chemical energy for other organisms of food chains to use, and this process is called photosynthesis (C3). Autotrophic plants produce their own nourishment, unlike animals (C1). Therefore, photosynthesizing plants are producers of the food chain (C2). However, only a small amount of energy is transmitted to the next trophy level of the food chain. Energy bypass occurs because each trophy level uses energy to carry out their own life processes and functions (C5). Plants also play a role in material cycling in the ecosystem (C4). All in all, plants play a crucial role in the ecosystem from the sustainability point of view (C6). 
A model answer for task B, formulated by two biology university lecturers (with macro-concepts bolded and the contexts relevant for the analysis numbered in parentheses):

Explain the role of plants in the ecosystem from the viewpoint of the composition of the atmosphere.

In photosynthesis, the plants absorb carbon dioxide from the atmosphere and release oxygen (C1). Thus, as a result of photosynthesis, the gas balance in the atmosphere is favorable and stable, which has enabled current modes of life to evolve (C2). Plants also play a role in material cycling in the ecosystem (C3). Carbon dioxide is a greenhouse gas, the increase of which is a reason for ongoing climate change (C4). Thus, plants and, particularly, forests are carbon sinks that are important for ecosystems from a sustainability perspective.

The lengths of the answers for the two questions were both restricted to six lines. Students gave their answers individually in a regular lecture hall context in September 2019, and they had approximately 30 min to complete the tasks.

\subsection{Data Analysis}

The lexical networks to be analyzed here were constructed from students' written answers, and such so-called lexicons play a key role in analyzing how students use different concepts and words in their answers [31,32,36]. To construct a stratified lexical network, a text analysis of students' written answers is performed, based on a grammatical sentence analysis in which special attention is paid to nouns and verbs, while the text analysis itself concentrates only on grammar and syntax. First, written answers were modified into simple sentences. In the simplification process, subordinate clauses are transformed into main clauses. Second, nouns are recognized, and the root verb is identified for each main clause. Third, the sentences are classified into contexts that are defined based on the model answers of university lecturers and students' answers (Appendix A). If a certain sentence was a mixture of more than one context, the decision of context was made based on the dominance or the precedence of the content. This means that if it was possible to identify the most emphasized aspect of the sentence, that ruled the context. In cases where the contexts were equally stressed, the first aspect within a sentence ruled the context where the sentence would be categorized. This was not common among answers since most of the sentences belonged clearly to only one context. Therefore, such choices do not greatly affect the results. The lexical analysis of the answers, and especially the decisions regarding which context the answers belong to, was carried out by two experts who followed a detailed analysis protocol. The interrater agreement of the context classifications was $69.9 \%$ for task A and $79.3 \%$ for task B. The simplified text structure was then transformed into lexical networks, where tag word nodes are connected to root verb nodes, and root verbs are connected to contexts. A more detailed description of the method is provided in Appendix B.

To construct the lexicon, we have first constructed a tiered lexical network, reflecting the position of a noun in either the clause, sentence or context. These constructs are not discussed in detail here because they are used only as auxiliary representations to quantify the lexical distance (for details, see [31,32]). The lexical distance of the terms and words in the lexical network is next quantified by using a so-called communicability centrality (more briefly, communicability in what follows) of nodes in the lexical network. Communicability describes the lexical support that the node $(q)$ receives from other nodes. A pair of nodes that have high mutual communicability are close in the sense that they can easily reach (communicate with) each other, while those with low communicability are distant and cannot reach (communicate with) each other easily. Communicability is a global centrality measure characterizing the position of a node in a network. Moreover, as its name suggests, it is designed to describe how nodes can communicate or, alternatively, how the information content of a node can be passed to other nodes in the network (for the basic theory and construction of communicability measures, see, e.g., [37], for applications in lexical networks, see [31]). The computation of communicability as used here is explained 
in more detail in Appendix B, closely following the steps as presented elsewhere in more detail $[31,32]$.

The communicability between words is great in two obvious cases: first, when the given words (p) and (q) occur often in the same sentence; second, when many paths, even long ones, connect the words through a connection at deeper semantic levels. In both cases, one should take the word to have an important position in the network. The lexical networks are pruned by removing auxiliary and loosely connected words. The nodes that have low values of communicability are loosely connected within the network of connected terms and are thus auxiliary. By removing those nodes that fall below a prescribed threshold (in practice, having only a relative value of 0.30 of the maximal values of communicability of the most well-connected nodes) we create a lexical proximity network (LPN) retaining only the best-connected nodes. This lexical proximity network, which is a pruned version of the full lexical network, is called the lexicon.

The lexicon defined in this manner contains a summary of the information about the connections that students explicated in their answers about the role of plants in the ecosystem. A representation of the lexical information is produced from the lexical networks, in order to find out which terms play an important role in students' answers. It should be noted that here, the "importance" of a term means that it should have a key role in the totality of the answer, as part of an explanatory sentence or context-related set of sentences. Terms and words that are only listed in passing are dropped as auxiliary, unconnected terms. Obviously, by listing words, students show that they know the words, but the written answers do not reveal the way they use the words in an explanatory sentence or sentences as being central or important. Therefore, simply listing words is not counted in the present analysis as a sign of their importance.

\section{Results}

\subsection{Concepts and Terms in Students' Written Answers}

The first research question aimed to find out which concepts first-year life science students use in their answers when considering the role of photosynthesizing plants in the ecosystem from the food chain point of view (task A) and from the viewpoint of the composition of the atmosphere (task B). The frequencies of use for concepts and words are presented in Tables 1 and 2. The tables show that the most common concepts are clearly distinguishable and, respectively, a great number of concepts are mentioned only a few times.

In task A, the most common concepts, "the plant" and "food chain", were mentioned in the task instruction. The most frequent concepts introduced by the students were "energy", "producer", "organism" and "nourishment", most of which can be classified as macro-concepts related to the phenomenon of photosynthesis. These concepts are relevant in explaining the role of plants as primary producers in the biosphere. The occurrences of the concept of photosynthesis are relatively few in number. Furthermore, certain central concepts, such as "the Sun" or "light energy", associated with the origin of energy received relatively few mentions. Even fewer concepts related to the idea of the bypass of energy from the food chains were mentioned in the task for measuring students' understanding of the role of the plants from the point of view of the food chain.

Significantly fewer concepts and words were used in task B compared to task A. In task $\mathrm{B}$, the most common concepts used were "the plant" and "the atmosphere", both mentioned in the assignment instruction. The concepts of "oxygen" and "carbon dioxide", initially presented by the students, occurred frequently. Macro-concepts, such as "photosynthesis" and "carbon sink", were mentioned, but not very often. The concept of "greenhouse gas" existed to some extent, but other related concepts, such as "climate change" and "greenhouse effect", were not mentioned in most of the answers. 
Table 1. The frequency of concepts and words that the students used in their answers for task A (including terms mentioned at least seven times).

\begin{tabular}{|c|c|c|c|c|c|}
\hline Concept/Word & Frequency & Concept/Word & Frequency & Concept/Word & Frequency \\
\hline plant* & 286 & organic & 22 & link & 11 \\
\hline food chain * & 130 & the second & 19 & usable & 8 \\
\hline energy & 127 & important & 19 & carbon dioxide & 8 \\
\hline producer & 110 & large & 19 & carbon & 8 \\
\hline organism & 81 & form & 19 & nutrition & 8 \\
\hline nourishment & 66 & trophy level & 16 & aid & 8 \\
\hline consumer & 51 & role * & 16 & heterotrophic & 8 \\
\hline ecosystem * & 34 & decomposer & 16 & food source & 8 \\
\hline autotrophic & 33 & dependent & 15 & step & 7 \\
\hline the first & 32 & oxygen & 15 & carnivore & 7 \\
\hline biomass & 30 & substance & 15 & life & 7 \\
\hline Sun & 29 & inorganic & 14 & animal & 7 \\
\hline grade & 28 & solar energy & 13 & energy source & 7 \\
\hline herbivore & 25 & sugar & 13 & primary production & 7 \\
\hline glucose & 32 & photosynthesis & 11 & & \\
\hline
\end{tabular}

Macro-concepts are bolded. ${ }^{*}=$ this concept was mentioned in the task instruction.

Table 2. The frequency of concepts and words that students used in their answers for task B.

\begin{tabular}{cccc}
\hline Concept/Word & Frequency & Concept/Word & Frequency \\
\hline plant & 232 & concentration of carbon & 15 \\
atmosphere & 197 & dioxide & 14 \\
oxygen & 172 & concentration of oxygen & 12 \\
carbon dioxide & 162 & climate & 11 \\
photosynthesis & 41 & carbon assimilation & 11 \\
organism & 40 & greenhouse gas & 9 \\
carbon & 33 & water & 9 \\
composition & 30 & nitrogen & 9 \\
carbon sink & 29 & side product & 9 \\
air & 25 & role * & 9 \\
cell respiration & 22 & concentration & 8 \\
life & 17 & photosynthesizing & 7 \\
globe & 16 & &
\end{tabular}

\subsection{Network of Concepts}

Our second aim was to investigate students' understanding related to the role of plants in the ecosystem by exploring their conceptual networks more profoundly. This was achieved by utilizing the network approach to describe the proximity of key terms in students' lexicons. Communicability measures, which describe the number of different routes between concepts, were calculated for all concepts. A concept that has a higher communicability ranking (see Tables 3 and 4) compared to its frequency ranking (see Tables 1 and 2) is globally more important. For example, the macro-concept of energy gets a higher importance value in this inspection, indicating that the concept was central to students' answers. On the other hand, the difference between tasks A and B becomes even clearer in this inspection, and in task B, the number of concepts is even lower when we explored communicability rankings compared to the occurrence frequency of concepts. 
Table 3. Normalized communicability ranking of concepts and words that students used in task A.

\begin{tabular}{|c|c|c|c|c|c|}
\hline Concept/Word & Comm. & Concept/Word & Comm. & Concept/Word & Comm. \\
\hline plant* & 1.000 & inorganic & 0.427 & structure & 0.290 \\
\hline energy & 0.856 & carbon & 0.424 & water & 0.289 \\
\hline organism & 0.829 & compound & 0.419 & life process & 0.287 \\
\hline food chain * & 0.801 & heterotrophy & 0.415 & life & 0.270 \\
\hline nourishment & 0.778 & chemical & 0.408 & carnivore & 0.245 \\
\hline producer & 0.670 & source of nourishment & 0.393 & carbon assimilation & 0.244 \\
\hline consumer & 0.655 & heterotroph & 0.389 & terrestrial ecosystem & 0.224 \\
\hline the first & 0.625 & species & 0.389 & soil & 0.218 \\
\hline organic & 0.606 & herbivorous animal & 0.364 & metabolism & 0.216 \\
\hline biomass & 0.591 & nature & 0.362 & light & 0.201 \\
\hline ecosystem * & 0.579 & primary production & 0.358 & element & 0.200 \\
\hline trophy level & 0.566 & self-sufficient & 0.347 & ground & 0.200 \\
\hline living organism & 0.552 & food web & 0.339 & process & 0.179 \\
\hline animal & 0.551 & sunlight & 0.336 & atmosphere & 0.171 \\
\hline the second & 0.545 & alga & 0.335 & autotrophic & 0.158 \\
\hline herbivore & 0.531 & nutrient & 0.317 & herbivore & 0.152 \\
\hline sugar & 0.522 & cell respiration & 0.300 & diversity & 0.147 \\
\hline glucose & 0.516 & photosynthesis & 0.299 & circulation & 0.129 \\
\hline Sun & 0.490 & substance & 0.295 & molecule & 0.127 \\
\hline decomposer & 0.479 & increase & 0.295 & Earth & 0.093 \\
\hline predator & 0.456 & carbon dioxide & 0.293 & bypass & 0.044 \\
\hline \multirow[t]{2}{*}{ autotrophy } & 0.445 & oxygen & 0.291 & insect & 0.023 \\
\hline & & & & food substance & 0.000 \\
\hline
\end{tabular}

Macro-concepts are with background colour. ${ }^{*}=$ this concept was mentioned in the task instruction.

Table 4. Normalized communicability ranking of concepts and words that students used in task B.

\begin{tabular}{cc}
\hline Concept/Word & Comm. \\
\hline plant & 1.000 \\
carbon dioxide & 0.848 \\
oxygen & 0.837 \\
carbon & 0.570 \\
ecosystem * & 0.245 \\
life & 0.228 \\
biomass & 0.214 \\
glucose & 0.206 \\
producer & 0.180 \\
organic & 0.085 \\
Sun & 0.000 \\
\hline
\end{tabular}

Macro-concepts are with background colour. ${ }^{*}=$ this concept was mentioned in the task instruction.

The conceptual proximity networks that were constructed, based on the communicability rankings of concepts for tasks A and B, are shown in Figure 1. These networks show only those concepts and terms that are connected to each other. The proximity network shows whether there are connections between concepts with many different routes. In Figure 1, we have drawn logarithmic values for communicability rankings in a diagrammatic form, in order to make the exponential values easier to compare with each other. Concepts that have only one connection to another concept drop out as unconnected concepts. This means that merely listing words is not counted as a sign of their importance.

This inspection reveals that the networks related to tasks A and B differed significantly. In task $A$, the conceptual proximity network was richer and included qualitatively different types of concepts compared to task B. In task A, the core layer of the conceptual network consisted of macro-concepts (e.g., energy, nourishment), whereas, in task B, the concepts that were found to be connected were mainly factual, such as chemical compounds (oxygen, carbon, carbon dioxide). In general, students' answers for task B remained at a more superficial level. 
(a)

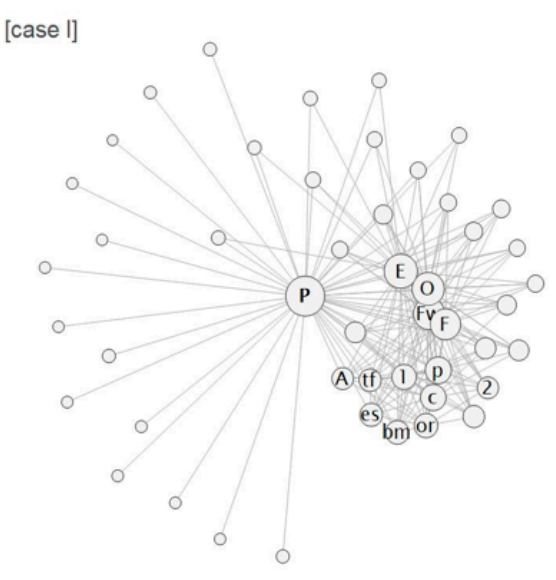

(b)

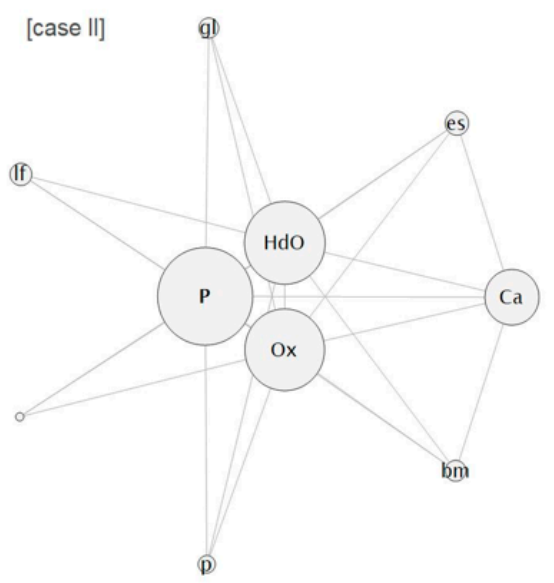

Figure 1. Left side (a), task A: Explain the role of plants in the ecosystem from the viewpoint of the composition of the atmosphere. $\mathrm{P}=$ plant; $\mathrm{F}=$ nourishment; $\mathrm{E}=$ energy; $\mathrm{Fw}=$ food chain; $\mathrm{O}=$ organism; $\mathrm{p}=$ producer $\mathrm{c}=$ consumer; or $=$ organic $; 1=$ the first $; 2=$ the second bm = biomass; $\mathrm{tf}=$ trophy level; es = ecosystem; $\mathrm{A}=$ animal. Right side (b), task B: Explain the role of plants in the ecosystem from the food chains point of view. $\mathrm{P}=$ plant; $\mathrm{Ox}=$ oxygen; $\mathrm{Ca}=$ carbon; $\mathrm{HdO}=$ carbon dioxide; $\mathrm{es}=$ ecosystem; $\mathrm{bm}=$ biomass; $\mathrm{p}=$ producer; $\mathrm{lf}=\mathrm{life} ; \mathrm{gl}=$ glucose .

\section{Discussion}

The purpose of this study was to investigate the incidence and interrelations of concepts in the verbal answers of first-year life science students concerning central biological contents, namely the role of photosynthesizing plants in the ecosystem, from the viewpoints of nourishment supply and the atmosphere. Students' written answers were investigated utilizing a specific conceptual network tool developed by the second and third authors of this article [31,32]. The analysis allows the exploring of both quantitative aspects (frequencies of terms used) and the interrelations between used terms (communicability). Based on previous studies, analysis of the extent of lexicons is a suitable qualitative method to evaluate students' level and quality of knowledge [cf. 31].

First-year life science university students are expected to construct an adequate conceptual knowledge base related to complex science phenomena, and simultaneously learn to use science language appropriately when communicating regarding science with teachers and peers. However, according to extensive previous research findings, this poses serious challenges for many university students [17]. Considering that a more integrated knowledge base at the beginning of university studies strongly predicts students' learning and achievement during further academic studies [38-40], a better understanding of the topic is important.

The results of this study showed that in the task measuring students' understanding of the role of plants from the food chain and nourishment supply perspective, the students used macro-concepts, such as "energy" and "producer", more than they used macroconcepts in their answers concerning the role of plants in the composition of the atmosphere. In the latter task, the students mainly operated with more superficial concepts, such as chemical compounds. Even though an understanding of chemical compounds is also indisputably important in biosciences, they are not considered as central macro-concepts in this context. In addition, although the assignment instructed students to consider the phenomena of photosynthesis and cell respiration on a global scale, certain central concepts that were present in the model answers of university teachers, such as "energy bypass", "climate change" and "greenhouse effect" were not mentioned in the answers of the students. These concepts connect the basic phenomenon of photosynthesis to current ecological challenges on a larger scale that, in twenty-first-century science learning, is 
increasingly important $[36,41]$. The result is in line with previous findings that university students often struggle with applying basic knowledge [10,42].

Furthermore, it became apparent that the concept networks were remarkably richer and included more links between the concepts when it came to the students' understanding of the role of photosynthesizing plants in the ecosystem from the food chain point of view, compared with their answers related to the role of photosynthesizing plants from the point of view of the atmosphere. Thus, students' understanding related to the role of plants in the constituents of the atmosphere was more superficial compared to their understanding of food chains and nourishment supply. Generally, the existence of macroconcepts seemed to be related to richer and higher-level answers, whereas the lack of macro-concepts was related to more superficial answers. This finding is in line with the idea that the development of macro-concepts shows a move toward more abstracted and integrated concepts in denser knowledge structures, allowing so-called systemic understanding $[10,43]$.

The first academic year is characterized as a strong predictor of future academic performance and achievement $[44,45]$, which highlights the importance of timely support for new students to appropriately develop their science understanding and skills early on. This requires university teachers as well as students to become aware of differences between everyday language and scientific language, particularly in terms of science concepts. Furthermore, supporting students to learn to meaningfully use the language of science and to focus on interrelated concepts and contents, instead of unconnected facts, in science classrooms would promote the high-level learning of complex scientific phenomena.

Due to the characteristics of scientific language [23], students may have difficulties in writing down the answers to given tasks because they are not familiar with using the language of science. Knowing these characteristics of scientific language develops gradually in the course of further university studies. Compared to texts that students are used to reading and writing, the characteristics of scientific language together make scientific texts dense, abstruse, and hard to read and write [23]. This can often lead to the student reproducing isolated facts instead of constructing a rich and flexible conceptual network. Knowing the characteristics of scientific language might help students to better understand the language of science. In addition, the learning of scientific language becomes even more difficult if students must learn science in a foreign language instead of in their mother tongue.

In general, the students' answers for open-ended tasks in this study were scanty, which may reflect prevailing practices that students assume to be the desired answering style. It has been stated that science textbooks often present scientific models as if readers have no prior knowledge or have only relevant prior knowledge about the topic to be learned [46,47]. Furthermore, biological processes are often presented separately in textbooks, which may hinder the construction of interrelations between the concepts [48]. Even though it has been recognized that when learning science, fostering students' skills in conceptual understanding, problem-solving and scientific thinking are valuable objectives in creating a comprehensive understanding of the given subject (see, e.g., [49]), very little attention is paid to the coherence and cohesion of written tasks. An important question for future research is how study programs in higher education can build on these observations to support students in constructing a solid and well-organized knowledge base.

The following aspects need to be considered when generalizing the results outlined in this paper. Firstly, the majority of the participants in this study were female students, which is typical of the population from which this sample was drawn (i.e., majors in biology, environmental sciences and molecular biosciences). Additionally, in this study, the answering space for open-ended tasks was restricted via lines that might have influenced the answering style into being more compact and list-like than it would have been without restriction.

Furthermore, the representations of linguistic networks depend strongly on the text on which they are based, and the decisions when forming contexts also have a great impact 
on forming the linguistic network. In a linguistic network, there is a connection between two words if they appear often in the same context. However, the definition of contexts determines what counts as a connection in a linguistic network. The research objectives guide that definition and, therefore, different research setups can result in very different linguistic networks, even from the same data. In this sample, the connections between concepts are formed through single sentences. This means that there are no connections between sentences, i.e., text cohesion is missing in the students' answers, or this method is not able to identify it.

\section{Conclusions}

Learning scientific knowledge, especially counterintuitive concepts regarding phenomena of the physical and biological world, is hard and, typically, it requires a considerable restructuring of students' initial knowledge. Furthermore, university students are required not only to learn new science knowledge but also new competencies in order to use the language of science appropriately. The results of this study indicate that network analysis method provides important insights into life science students' understanding, and their abilities to operate with science language related to complex environmental and socioeconomic phenomena. In addition, the results show that in science classrooms, paying attention to students' conceptions of the basic science phenomena that underlie current sustainability challenges is relevant. For example, understanding the role of photosynthesizing plants, which forms the basis for all the energy sources essential to life and regulating the budgets of atmospheric gases, e.g., carbon dioxide, is needed in order to understand the current climate crisis and the questions related to nourishment production for a growing population. Future science experts are today's university students, who will need to be equipped with a high level of scientific knowledge and reasoning skills to solve complex and unforeseen serious problems. The results presented in this article can hopefully inspire further research and serve to guide university science educators in supporting students' systemic understanding in biology classrooms.

Author Contributions: Conceptualization, I.S., M.N. and I.T.K.; methodology, I.S., M.N. and I.T.K.; software, M.N. and I.T.K.; validation, I.S. and M.N.; formal analysis, I.S., M.N. and I.T.K.; investigation, I.S. and M.N.; resources, I.S.; data curation, I.S.; writing-original draft preparation, I.S. and M.N.; writing—review and editing, I.S., M.N. and I.T.K.; visualization, I.T.K.; funding acquisition, I.S. and I.T.K. All authors have read and agreed to the published version of the manuscript.

Funding: We thank the University of Helsinki for supporting this research paper via the project of Cultivating Expertise in the Learning of Life Sciences, CELLS (Research Funds of the University of Helsinki, HY/716/05.01.07/2018). This work was also funded by the Academy of Finland through grant number 311449 .

Institutional Review Board Statement: Voluntary participation, informed consent, and anonymity of the participants were ensured in the research process. The study did not involve intervention in the physical integrity of the participants, deviation from informed consent, studying children under the age of 15 without parental consent, exposure to exceptionally strong stimuli, causing long-term mental harm beyond the risks of daily life, or risking participants' security (cf. Finnish Advisory Board on Research Integrity 2019). Consequently, this study did not require a Finnish ethics review.

Informed Consent Statement: Informed consent was obtained from all subjects involved in the study.

Data Availability Statement: The data presented in this study are available on request from the corresponding author.

Acknowledgments: We thank the open access funding provided by University of Helsinki and we also thank the students who participated in this study. The authors express their warm thanks to research assistant B.Sc. Tomi Kiviluoma and Ph.D. student Karoliina Vuola, who carried out the lexical analysis for raw data.

Conflicts of Interest: The funders had no role in the design of the study; in the collection, analyses, or interpretation of data; in the writing of the manuscript; or in the decision to publish the results. 


\section{Appendix A}

Contexts in task A: "Explain the role of plants in the ecosystem from the food chain point of view".

Context 1-Self-sufficiency of photosynthesizing plants:

C1 Produce their own nourishment.

Context 2-The role of plants as producers in the ecosystem.

C1 Convert solar energy to chemical energy.

C2 Produce nourishment and $\mathrm{O}_{2}$.

C3 Role as primary producer/the first link in the food chain.

C4 Other organisms are dependent on them.

Context 3-The role of plants in energy flow in the food chain:

C1 Sunlight as the origin of the energy.

C2 The plants enable energy transmission in the food chain, from herbivores to carnivores and decomposers.

Context 4-The role of plants in the cycling of matter in the ecosystem:

C1 Circulation of nutrients.

C2 Circulation of water.

C3 Circulation of $\mathrm{O}_{2}$.

Context 5-Bypass of energy in the food chain:

C1 Only a modest part of the solar energy is used in the photosynthesis process.

C2 Most of the photosynthesized energy is used by the organism's own metabolism.

Context 6-The role of plants from the point of view of the sustainability of the ecosystem:

C1 Produce/store $\mathrm{CO}_{2}$.

C2 Release $\mathrm{O}_{2}$.

C3 The plants as carbon sinks/"lungs of the earth".

Contexts in task B: "Explain the role of plants in the ecosystem from the viewpoint of composition of the atmosphere".

Context 1 -The role of plants as the regulator of optimal atmospheric composition:

$\mathrm{C} 1$ Gas exchange: photosynthesizing plants bind $\mathrm{CO}_{2}$ and produce $\mathrm{O}_{2}$.

C2 The role of plants as "lungs of the earth".

C3 The role of plants as carbon sinks.

$\mathrm{C} 4$ The role of plants from the atmospheric humidity perspective.

$\mathrm{C} 5 \mathrm{O}_{2}$ plays a role in $\mathrm{O}_{3}$ formation.

Context 2-The role of plants in the origin of current life:

$\mathrm{C} 1$ Due to photosynthesizing plants, the $\mathrm{O}_{2}$ and $\mathrm{CO}_{2}$ levels of the atmosphere are suitable for current life modes.

C2 Without photosynthesizing plants, the atmospheric level of $\mathrm{O}_{2}$ would be higher and the level of $\mathrm{CO}_{2}$ would be higher.

C3 A suitable atmospheric level of $\mathrm{O}_{2}$ is a prerequisite for organisms.

C4 Cell respiration: $\mathrm{CO}_{2}$ and $\mathrm{O}_{2}$ enable respiration.

Context 3-The role of plants in the cycling of matter:

$\mathrm{C} 1$ The plants absorb and transpire water.

$\mathrm{C} 2$ As the plant dies, the substances from it get released back into the soil.

C3 The plants play a role in the cycling of carbon/oxygen and nitrogen.

Context 4-The role of plants from the climate change perspective:

$\mathrm{C} 1 \mathrm{~A}$ high atmospheric level of $\mathrm{CO}_{2}$ has a heating effect on the planet.

C2 Current climate change/global warming may at first accelerate the growth of global vegetation. 
C3 A decrease of living plant biomass leads to the acceleration of global warming. $\mathrm{C} 4$ Plants' increased ability to absorb $\mathrm{CO}_{2}$ helps mitigate climate change/global warming.

Context 5-The role of plants considered without appropriate connection to the task:

$\mathrm{C} 1 \mathrm{Cell}$ respiration: the plants' respiration releases $\mathrm{CO}_{2}$.

C2 The plants produce glucose/energy/biomass.

C3 Description of the consequences of global warming.

C4 The role of other photosynthesizing organisms except for plants.

\section{Appendix B}

Method

The lexical (or conceptual) networks are built here on the basis of how often the same words and terms occur at different levels, from the syntactic level (clauses) to the semantic level (contexts). Such connections form a stratified lexical network that bears information of the lexical distance of terms at different levels of syntax (for details, see [31,32]).

The method to quantify the connectivity between terms in the lexical network is based on a measure called communicability centrality [37] that pays attention to the different contiguous paths found between nodes (terms) in the lexical network. The paths can be weighted according to their lengths. The counting of such paths is used to measure lexical proximity. This measure tells how a node can pass information to other nodes through the network.

A lexical network that has $N$ nodes can have (at most) $N \times(N-1)$ different links between the nodes (terms). We can describe such a network by using adjacency matrix $\mathbf{A}$, in which elements $[\mathbf{A}]_{p q}=a_{p q}$ have a value of 1 if there is a connection between nodes $p$ and $q$, and a value of 0 if the nodes are not connected. We can use adjacency matrix $\mathbf{A}$ to calculate the number of different paths between two nodes in the lexical network.

The number of long paths increases almost factorially in a well-connected network. Therefore, we are interested in the relative weight of these paths, and the solution is to divide the number of walks by the factorial. This is called the communicability measure [37]:

$$
G_{p q}(\beta)=\frac{1}{1 !} \beta^{1}\left[\mathbf{A}^{1}\right]_{p q}+\frac{1}{2 !} \beta^{2}\left[\mathbf{A}^{2}\right]_{p q}+\frac{1}{3 !} \beta^{3}\left[\mathbf{A}^{3}\right]_{p q}+\ldots=\left[e^{\beta \mathbf{A}}-\mathbf{1}\right]_{p q}
$$

where e $\left[\ldots\right.$ ] is the matrix exponential, $\mathbf{1}$ the identity matrix, and $[\ldots]_{\mathrm{pq}}$ is its element at row $p$ and column $q$. Note that here, a slightly modified version of the standard definition of communicability [37] is used for convenience. The communicability has a free parameter $\beta \geq 1$. Parameter $\beta$ adjusts how wide the part of the network we look at should be when counting the paths. The optimal value for parameter $\beta$ offers the best diversity of terms at the lowest possible value of $\beta$. The optimal value seems here to be about $\beta=1$.

We can construct a lexical proximity network of key words and terms, where terms and words are linked according to their lexical distances. This modified and pruned lexical network, which contains only those terms and words that are connected well enough (exceeding a given threshold of proximity), is called a lexicon.

\section{References}

1. Duit, R.; Treagust, D.F. Conceptual change: A powerful framework for improving science teaching and learning. Int. J. Sci. Educ. 2003, 25, 671-688. [CrossRef]

2. Posner, G.J.; Strike, K.A.; Hewson, P.W.; Gertzog, W.A. Accommodation of a scientific conception: Toward a theory of conceptual change. Sci. Educ. 1982, 66, 211-227. [CrossRef]

3. Vosniadou, S. (Ed.) Conceptual change in learning and instruction: The framework theory approach. In International Handbook of Research on Conceptual Change, 2nd ed.; Routledge: New York, NY, USA, 2013; pp. 11-30.

4. Crane, L.; Winterbottom, M. Plants and photosynthesis: Peer assessment to help students learn. J. Biol. Educ. 2008, 42, 150-156. [CrossRef] 
5. Mintzes, J.J.; Wandersee, J.H. Research in science teaching and learning: A human constructivist view. In Teaching Science for Understanding: A Human Constructivist View; Mintzes, J.J., Wandersee, J.H., Novak, J.D., Eds.; Academic Press: San Diego, CA, USA, 2005; pp. 59-92.

6. Ross, P.; Tronson, D.; Ritchie, R.J. Modelling photosynthesis to increase conceptual understanding. J. Biol. Educ. 2005, 40, 84-88. [CrossRef]

7. Flaig, M.; Simonsmeier, B.A.; Mayer, A.-K.; Rosman, T.; Gorges, J.; Schneider, M. Conceptual change and knowledge integration as learning processes in higher education: A latent transition analysis. Learn. Individ. Differ. 2018, 62, 49-61. [CrossRef]

8. Södervik, I.; Mikkilä-Erdmann, M.; Vilppu, H. Promoting the Understanding of Photosynthesis among Elementary School Student Teachers through Text Design. J. Sci. Teach. Educ. 2014, 25, 581-600. [CrossRef]

9. Sinatra, G.M.; Pintrich, P.R. Intentional Conceptual Change; Lawrence Erlbaum Associates: Mahwah, NJ, USA, 2003.

10. Boshuizen, H.P.A.; Gruber, H.; Strasser, J. Knowledge restructuring through case processing: The key to generalise expertise development theory across domains? Educ. Res. Rev. 2020, 29, 100310. [CrossRef]

11. Krieger, J.; Gallois, C. Translating Science: Using the Science of Language to Explicate the Language of Science. J. Lang. Soc. Psychol. 2017, 36, 3-13. [CrossRef]

12. Kinchin, I.M.; De-Leij, F.A.A.M.; Hay, D.B. The evolution of a collaborative concept mapping activity for undergraduate microbiology students. J. Furth. High. Educ. 2005, 29, 1-14. [CrossRef]

13. Kinchin, I.M.; Hay, D.B.; Adams, A. How a qualitative approach to concept map analysis can be used to aid learning by illustrating patterns of conceptual development. Educ. Res. 2000, 42, 43-57. [CrossRef]

14. Nousiainen, M. Coherence of Pre-service Physics Teachers' Views of the Relatedness of Physics Concepts. Sci. Educ. 2013, 22, 505-525. [CrossRef]

15. McClure, J.R.; Sonak, B.; Suen, H.K. Concept map assessment of classroom learning: Reliability, validity, and logistical practicality. J. Res. Sci. Teach. 1999, 36, 475-492. [CrossRef]

16. Södervik, I.; Hanski, L.; Katajavuori, N. First-year pharmacy students' prior knowledge correlates with study progress and reveals different dynamics of misconceptions. Pharm. Educ. 2020, 20, 94-102. [CrossRef]

17. Södervik, I.; Mikkilä-Erdmann, M.; Chi, M.T.H. Conceptual change challenges in medicine during professional development. Int. J. Educ. Res. 2019, 98, 159-170. [CrossRef]

18. Wiser, M.; Amin, T. "Is heat hot?" Inducing conceptual change by integrating everyday and scientific perspectives on thermal phenomena. Learn. Instr. 2001, 11, 331-355. [CrossRef]

19. Kinchin, I.M. Confronting problems presented by photosynthesis. Sch. Sci. Rev. 2000, 81, 69-75.

20. Park, M.; Liu, X. Assessing Understanding of the Energy Concept in Different Science Disciplines. Sci. Educ. 2016, 100, 483-516. [CrossRef]

21. Ford, A.; Peat, F.D. The Role of Language in Science. Found. Phys. 1988, 18, 1233-1242. [CrossRef]

22. Lemke, J. Talking Science: Language, Learning and Values. In Language and Educational Processes; Ablex Publishing Corporation: Norwood, NJ, USA, 1990.

23. Fang, Z. The language demands of science reading in middle school. Int. J. Sci. Educ. 2006, 28, 491-520. [CrossRef]

24. Yore, L.D.; Hand, B.; Goldman, S.R.; Hilderbrand, G.M.; Osborne, J.F.; Treagust, D.F.; Wallace, C.S. New Directions in Language and Science Education Research. Read. Res. Q. 2004, 39, 347-352.

25. Fang, Z.; Wei, Y. Improving middle school students' science literacy through reading infusion. J. Educ. Res. 2010, 103, 262-273. [CrossRef]

26. Glynn, S.M.; Muth, K.D. Reading and writing to learn science: Achieving scientific literacy. J. Res. Sci. Teach. 1994, 31, 1057-1073. [CrossRef]

27. Gelman, S.A.; DeJesus, J.M. The language paradox: Words invite and impede conceptual change. In Converging Perspectives on Conceptual Change: Mapping an Emerging Paradigm in the Learning Sciences; Amin, T.G., Levrini, O., Eds.; Routledge/Taylor Francis Group: England, UK, 2018; pp. 89-96.

28. Yun, E.; Park, Y. Extraction of scientific semantic networks from science textbooks and comparison with science teachers' spoken language by text network analysis. Int. J. Sci. Educ. 2018, 40, 2118-2136. [CrossRef]

29. Wellington, J.; Osborne, J. Language and Literacy in Science Education; McGraw-Hill Education: New York, NY, USA, 2001.

30. Araújo, T.; Banisch, S. Multidimensional analysis of linguistic networks. In Towards a Theoretical Framework for Analyzing Complex Linguistic Networks; Mehler, A., Lücking, A., Banisch, S., Blanchard, P., Job, B., Eds.; Springer: Berlin/Heidelberg, Germany, 2016; pp. 107-131.

31. Nousiainen, M.; Koponen, I. Pre-service teachers' declarative knowledge of wave-particle dualism of electrons and photons: Finding lexicons by using network analysis. Educ. Sci. 2020, 10, 76. [CrossRef]

32. Koponen, I.; Nousiainen, M. Lexical Networks and Lexicon Profiles in Didactical Texts for Science Education. In Complex Networks and Their Applications VIII; Cherifi, H., Gaito, S., Mendes, J., Moro, E., Rocha, L., Eds.; COMPLEX NETWORKS 2019, Studies in Computational Intelligence; Springer: Cham, Switzerland, 2020; Volume 882. [CrossRef]

33. Baslam, M.; Mitsui, T.; Hodges, M.; Priesack, E.; Herritt, M.; Aranjuelo, I.; Sanz-Sáez, Á. Photosynthesis in a Changing Global Climate: Scaling Up and Scaling Down in Crops. Front. Plant Sci. 2020, 11, 882. [CrossRef]

34. Janssen, P.J.; Lambreva, M.D.; Plumeré, N.; Bartolucci, C.; Antonacci, A.; Buonasera, K.; Frese, R.N.; Scognamiglio, V.; Rea, G. Photosynthesis at the forefront of a sustainable life. Front. Chem. 2014, 2, 36. [CrossRef] [PubMed] 
35. Wandersee, J.H.; Schussler, E.E. Preventing plant blindness. Am. Biol. Teach. 1999, 61, 82-86. [CrossRef]

36. Koponen, I. Usage of terms "science" and "scientific knowledge" in Nature of Science (NOS): Do their lexicons in different accounts indicate shared conceptions? Educ. Sci. 2020, 10, 252. [CrossRef]

37. Estrada, E. The Structure of Complex Networks: Theory and Applications; Oxford University Press: Oxford, UK, 2012.

38. Araujo, A.M.; Leite, C.; Costa, P.; Costa, M.J. Early identification of first-year students at risk of dropping out of high-school entry medical school: The usefulness of teachers' ratings of class participation. Adv. Health Sci. Educ. 2019, 24, 251-268. [CrossRef] [PubMed]

39. Hailikari, T.; Nevgi, A. and Lindblom-Ylänne, S. Exploring alternative ways of assessing prior knowledge, its components and their relation to student achievement. Stud. Educ. Eval. 2007, 33, 320-337. [CrossRef]

40. Mennen, J.; van der Klink, M. Is the first-year predictive for study success in subsequent years? Findings from a academy of music. Music. Educ. Res. 2017, 19, 339-351. [CrossRef]

41. Jacobson, M.J.; Markauskaite, L.; Portolese, A.; Kapur, M. Lai, P.K.; Roberts, G. Designs for learning about climate change as a complex system. Learn. Instr. 2017, 52, 1-14. [CrossRef]

42. Södervik, I.; Virtanen, V.; Mikkilä-Erdmann, M. Challenges in understanding photosynthesis in a university introductory biosciences class. Int. J. Sci. Math. Educ. 2015, 13, 733-750. [CrossRef]

43. Koponen, I.; Kokkonen, T.A. Systemic view of the learning and differentiation of scientific concepts: The case of electric current and voltage revisited. Frontline Learn. Res. 2014, 5, 140-166.

44. Jenert, T.; Postareff, L.; Brahm, T.; Lindblom-Ylänne, S. Editorial: Enculturation and development of beginning students. Z. Für Hochsch. 2015, 10, 9-21. [CrossRef]

45. Trautwein, C.; Bosse, E. The first year in higher education-critical requirements from the student perspective. High. Educ. 2017, 73, 371-387. [CrossRef]

46. Chambliss, M.J. The characteristics of well-designed science textbooks. In The Psychology of Science Text Comprehension; Otero, J., Leön, J., Graesser, A.C., Eds.; Erlbaum: Mahwah, NJ, USA, 2002; pp. 51-72.

47. Mikkila-Erdmann, M. Text comprehension and conceptual change: Interaction between text design and levels of text comprehension. In Reframing the Processes of Conceptual Change: Integrating Theory and Practice; Mason, L., Limon, M., Eds.; Kluwer Academic Publishers: Amsterdam, The Netherlands, 2002; pp. 337-356.

48. Barak, J.; Sheva, B.; Gorodetsky, M. As "process" as it can get: Students' understanding of biological processes. Int. J. Sci. Educ. 1999, 21, 1281-1292. [CrossRef]

49. Crouch, C.H.; Mazur, E. Peer instruction: Ten years of experience and results. Am. J. Phys. 2001, 69, 970-977. [CrossRef] 